\title{
Synthesis of Amine-Type Adsorbents with Emulsion Graft Polymerization of 4-Hydroxybutyl Acrylate Glycidylether
}

\author{
Hongjuan $\mathrm{Ma}^{1}$, Kazuaki Morita ${ }^{2}$, Hiroyuki Hoshina ${ }^{1}$, Noriaki Seko ${ }^{1}$ \\ ${ }^{1}$ Quantum Beam Science Directorate, Japan Atomic Energy Agency, Takasaki, Japan; ${ }^{2}$ Graduate School of Engineering, Gunma \\ University, Kiryu, Japan \\ Email: ma.hongjuan@jaea.go.jp
}

Received February $16^{\text {th }}, 2011$; revised February $21^{\text {st }}, 2011$; accepted May $21^{\text {st }}, 2011$.

\begin{abstract}
Radiation induced graft polymerization on polymeric matrix followed by functionalization is widely accepted for the preparation of metal adsorbents. In this paper, a pre-irradiation method was used for emulsion graft polymerization of 4-hydroxybutyl acrylate glycidylether (4-HB) onto polyethylene/polypropylene (PE/PP) nonwoven fabric. The degree of grafting $\left(D_{g}\right)$ which can be calculated by weight increment was determined as a function of reaction time, irradiation dose, and monomer concentration. After 30 kGy irradiation, with 4-HB concentration of 5\%, surfactant Span 20 of $0.5 \%$ at $40^{\circ} \mathrm{C}$ for $2 \mathrm{~h}$, the trunk polymer was made grafted at a $D_{g}$ of $135 \%$. 4-HB-grafted PE/PP nonwoven fabric was modified by ethylenediamine (EDA) in isopropyl alcohol (IPA) as a solvent at $60^{\circ} \mathrm{C}$. With a $D_{g}$ of $135 \%$, the amine group density of the adsorbent is $2.8 \mathrm{mmol} / \mathrm{g}$. The adsorption test was carried out by batch experiment in several metal ion solutions, and the removal ratio from the EDA modified adsorbent of the metal ions is in the order of $\mathrm{Cu}^{2+}>\mathrm{Pb}^{2+}>$ $\mathrm{Zn}^{2+}>\mathrm{Ni}^{2+}>\mathrm{Li}^{+}$. Compared with glycidyl methacrylate (GMA) which is a typical functional monomer for graft polymerization, 4-HB-grafted adsorbent exhibited not only better mechanical property but also higher adsorption capacity of $\mathrm{Cu}^{2+}$ and $\mathrm{Pb}^{2+}$.
\end{abstract}

Keywords: Graft Polymerization, Pre-irradiation, 4-hydroxybutyl Acrylate Glycidylether (4-HB), Glycidyl methacrylate (GMA), Amine-Type Adsorbent

\section{Introduction}

Aquatic pollution by heavy metals has attracted worldwide attention for many decades. Several heavy metals such as cadmium, chromium, copper, lead, mercury, nickel, zinc, etc. are included on the U.S. Environmental Protection Agency's (USEPA) list of priority pollutants [1]. Copper is an essential micronutrient, vital for the body in small amounts. However, humans can present symptoms from temporary stomach and intestinal disorders to kidney or liver damage at high amount over 1.3 $\mathrm{mg} \cdot \mathrm{dm}^{-3}[2]$. Lead intoxication has been a problem throughout history [3,4], adverse health effects of lead are well documented: it may cause severe damage to the kidney, nervous system, reproductive system, liver and brain and causes sickness or death $[4,5]$. The permissible limits for lead in drinking water given by USEPA are $0.015 \mathrm{mg} \cdot \mathrm{dm}^{-3}$ [6] and for wastewaters is $0.1 \mathrm{mg} \cdot \mathrm{dm}^{-3}$ given by both USEPA and Bureau of Indian Standards
(BIS) $[7,8]$. The potential sources of $\mathrm{Cu}^{2+}$ ions are, essentially, pulp, paper and wood preservative-employing mills, industrial waste streams of metal cleaning and plating baths, fertilizer industry, et al. [9]. Lead has been used for many years in products of everyday life (paint, household plumbing, water pipes and et al. [10-12]. Hence, both $\mathrm{Cu}^{2+}$ and $\mathrm{Pb}^{2+}$ ions are ubiquitous and frequently found toxic metals in surface water. And it becomes mandatory for the removal of lead from drinking and wastewaters. Therefore, several processes have been used and developed over years to remove such metals from industrial wastewater: biological process [13-15], ion exchange [16], membrane filtration [17,18], adsorption or electrochemical recovery $[19,20]$ et al. For the adsorption task, both inorganic $[21,22]$ and organic especially polymeric materials [23] have been explored successfully for years. Many techniques have been suggested in the literature for the synthesis of polymeric 
adsorbents [24,25].

The widespread interest in radiation-induced graft polymerization has largely been driven by the benefits of economical, clean and efficient. Under the irradiation of high-energy sources such as $\gamma$-ray or electron-beam, free radicals were generated in the polymeric material and these free radicals initiated the graft polymerization of the monomers (Figure 1). Therefore, polymeric grafts were covalently connected to the raw material, which can impart the raw material with desirable properties [26-30]. After chemical modifications the resulting polymers were widely applied for preparation of metal adsorbents to recover rare metals such as uranium recovery from seawater, rare metals from hot spring water, cadmium from scallop and et al. [26,31-33].

For the past decades glycidylmethacrylate (GMA) is considered to be the most widely used precursor monomer for graft polymerization, as the epoxy group can be modified easily into functional groups [34-36]. However, too much high $\mathrm{D}_{\mathrm{g}}$ would lead the brittleness of grafted material. Hence, 4-hydroxybutyl acrylate glycidylether (4-HB) was used to synthesize the metal ion adsorbent. 4-HB shares the similar molecular structure with GMA with an epoxy group at the end. The extra 4 methylene group of 4-HB makes the molecular structure longer than GMA (Figure 1). Therefore, the graft polymerization process and the absorptive property of modified adsorbents should be investigated.

In this paper the PE/PP nonwoven fabric (NF) was irradiated with electron beam in $\mathrm{N}_{2}$ atmosphere at dry ice temperature. Graft polymerization of 4-HB was carried out in emulsion in order to find the optimum conditions to prepare grafted PE/PP-g-P4-HB material. The degree of grafting $\left(\mathrm{D}_{\mathrm{g}}\right)$ was determined as a function of irradiation dose, monomer concentration and reaction time. Taking account of the high affinity of $\mathrm{N}$ and $\mathrm{S}$ donor containing ligands for metal ions such as $\mathrm{Cu}^{2+}, \mathrm{Pb}^{2+}, \mathrm{Zn}^{2+}$, $\mathrm{Ni}^{2+}$ [36], the selected PE-g-PGMA was modified with ethylenediamine (EDA). The main aim of this article is to elucidate the mild technique of radiation-induced graft polymerization of 4-HB on PE/PP NF and consequently to explore the feasibility of the radiation utilization method for recovering heavy and rare metals.

\section{Experimental}

\subsection{Materials}

Trunk material of nonwoven fabric (NF) composed of polyethylene-coated polypropylene (Kurashiki MFG Co., Osaka, Japan) was used as a trunk polymer for graft polymerization. 4-HB and GMA was purchased from Tokyo Kasei Kogyo Co. Ltd., Japan, and used without further purification. Ethylenediamine (EDA), sodium n-dodecyl sulfate (SDS), polyethylene glycol (PEG), sorbitan monolaurate (Span 20), polyoxyethylene sorbitan monolaurate (Tween 20), polyoxyethylene sorbitan palmitate (Tween 40), and polyoxyethylene sorbitan monostearate (Tween 60) and isopropyl alcohol (IPA), were purchased from Kanto Chemical Co., Ltd. Copper, lead, zinc, nickel, lithium standard solution for quantitative analysis (1000 ppm) and ultrapure nitric acid (ultrapure-100) were purchased from Kanto Chemical Co., Ltd. Potassium hydroxide were of analytical grade and used as received. Other chemicals of reagent grade such as methanol $(\mathrm{MeOH})$ and water from a Milli-Q purification system were used in washing treatments.

\subsection{Preparation of 4-HB Emulsion Solution}

An amount of 4-HB with certain surfactant such as SDS, PEG, Span 20, Tween 20, Tween 40 and Tween 60 were added into the water solution. The solution was mixed with a homogenizer at room temperature for $5 \mathrm{~min}$ to get

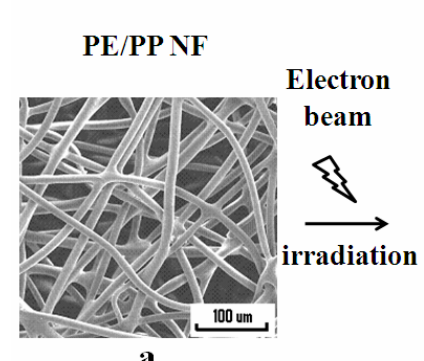

a

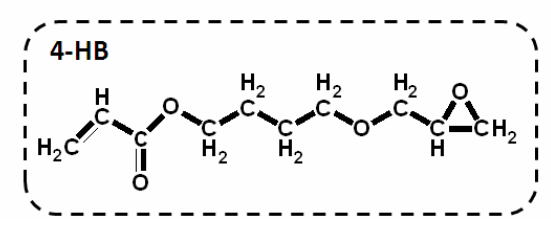

4-HB grafted NF

$D_{g}=135 \%$

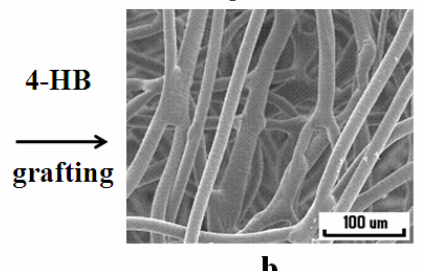

b

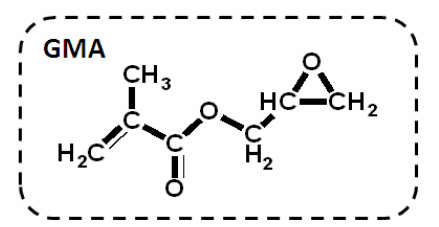

EDA modified NF

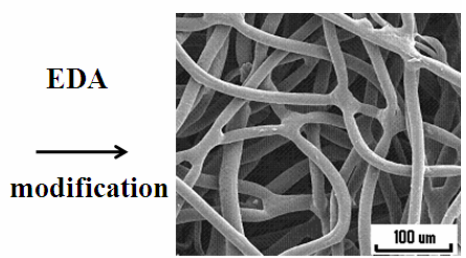

c

Figure 1. Preparation scheme of amine type adsorbent. 
a homogeneous emulsion state. The micelle size of 4-HB/Span 20 was evaluated by fiber optics dynamic light scattering spectrophotometer (FDLS-3000, Otsuka Electronics, Co. Ltd., Japan).

\subsection{Graft Polymerization and Chemical Modification}

The NF in long sheet was cut into $3 \mathrm{~cm} \times 7 \mathrm{~cm}$ square pieces which were then packed into polyethylene bags. After the replacement of the air in the polyethylene bag by nitrogen gas, the NF pieces were cooled at dry-ice temperature and exposed to an electron beam irradiation. The irradiated NF pieces were transferred to a glass ampoule and the air inside was evacuated to remove $\mathrm{O}_{2}$. Then, an aqueous emulsion containing 4-HB and Span 20 was drawn into the glass ampoule via suction. Graft polymerization of 4-HB was carried out by keeping the glass ampoule in a water bath at $40^{\circ} \mathrm{C}$. After the graft polymerization, the grafted NF pieces were washed three times with methanol and dried. After drying under the reduced pressure, the amount of 4-HB grafted onto NF was evaluated by the degree of grafting $\left(D_{g}\right) . D_{g}$ was defined as follows:

$$
\mathrm{D}_{\mathrm{g}}(\%)=\left(W_{\mathrm{i}}-W_{0}\right) / W_{0} \times 100,
$$

where, $W_{0}$ is the initial weight of NF and $W_{\mathrm{i}}$ weight of $\mathrm{NF}$ after graft polymerization.

4-HB-grafted NF was aminated by $70 \%$ EDA in IPA at $60^{\circ} \mathrm{C}$ to introduce the adsorption unit [37]. After $3 \mathrm{~h}$ reaction, the 4-HB-grafted NF was taken out from the solution, washed with distilled water. After drying under reduced pressure, the density of amine group of the adsorbent was estimated by:

Amine group density (mmol/g-adsorbent) $(\%)=\left(Z_{i}-\right.$ $\left.Z_{0}\right) / Z_{i} / M \times 100$,

where, $Z_{0}$ and $Z_{i}$ are the weights of 4-HB-grafted NF before and after chemical modification and $M$ the molecular weight of the EDA.

\subsection{Metal Adsorption}

Metal adsorption of the amine type adsorbent fabrics was performed by batch adsorption. $0.02 \mathrm{~g}$ EDA modified NF was soaked in $45 \mathrm{ml}$ of metal ions of $10 \mathrm{ppm}$. The removal ratio of metal ions was evaluated as follows:

$$
\text { Removal Ratio }(\%)=\left(C_{0}-C_{\mathrm{i}}\right) / C_{0} \times 100,
$$

where, $C_{0}$ and $C_{\mathrm{i}}$ are the concentrations of the metal ions in solution before and after adsorption.

\subsection{Analysis}

The graft polymerization of 4-HB-grafted NF was demonstrated by Fourier transform infrared (FT-IR) in a transmittance mode on a PerkinElmer Spectrum One FT-IR. The NF before and after graft polymerization was observed with a scanning electron microscope (SEM, Hitachi SEMDX Type N) after sputtered with gold. The concentration of the remaining metal ion was measured by optical emission spectrometer (Optima 4,300 DV).

\section{Results and Discussion}

\subsection{Emulsion Stability}

In order to get suitable graft polymerization condition the stability of 4-HB emulsion solution prepared by several different surfactants was investigated to optimize the grafting condition. $5 \mathrm{wt} \%$ of 4 -HB was added into $1 \mathrm{wt} \%$ certain surfactant water solution. The resulting emulsions of 4-HB with surfactant were in a milky state with different size of micelle after high speed magnetic stir by a homogenizer. For a stable emulsion not only the milky state but also the size of micelle should keep constant all along and their stabilities of homogeneous emulations states were summarized in Table 1. In the case of SDS and PEG the emulsion could not maintain a milky state and separated into layers within half an hour. Milky state prepared with Tween's maintained for $6 \mathrm{~h}$ and then gradually changed into separated layers (Figure 2(d)). The most stable emulsion of $5 \mathrm{wt} \% 4-\mathrm{HB}$ in water was obtained with the addition of Span 20, in which the milky state can keep for at least $24 \mathrm{~h}$ (Figure 2). In order to optimize the state of 4-HB/Span 20 emulsion, the concentration of Span 20 was changed and the result was shown in Figure 3. Obviously, the size of micelle increased from 200 to $600 \mathrm{~nm}$ when the concentration of Span 20 was reduced from 1.0 to $0.1 \mathrm{wt} \%$. Therefore, the optimal emulsion of 4-HB was obtained when the concentration of Span 20 was set at $0.5 \mathrm{wt} \%$.

\subsection{Graft Polymerization}

The NF was irradiated at five different irradiation doses: $10,20,30,40$ and $50 \mathrm{kGy}$ to investigate the effect of irradiation dose on $\mathrm{D}_{\mathrm{g}}$. The emulsion graft polymerization was carried out at $40^{\circ} \mathrm{C}$ in the aqueous emulsion of $5 \%$ 4 -HB and $0.5 \%$ Span 20. Figure 4 depicts the $\mathrm{D}_{\mathrm{g}}$ of $4-\mathrm{HB}$ onto the NF as a function of irradiation dose after $1 \mathrm{~h}$. The results indicated that the $\mathrm{D}_{\mathrm{g}}$ of 4-HB increased linearly with the increase of the absorbed dose below $40 \mathrm{kGy}$. Grafting saturation with a $\mathrm{D}_{\mathrm{g}}$ of $180 \%$ was achieved at

Table 1. Stability of 4-HB emulsion prepared by different surfactants.

\begin{tabular}{cc}
\hline Surfactant & Stability of milky state \\
\hline SDS & $<0.5 \mathrm{~h}$ \\
PEG & $<0.5 \mathrm{~h}$ \\
Span 20 & $24 \mathrm{~h}$ \\
Tween 20 & $6 \mathrm{~h}$ \\
Tween 40 & $6 \mathrm{~h}$ \\
Tween 60 & $6 \mathrm{~h}$ \\
\hline
\end{tabular}




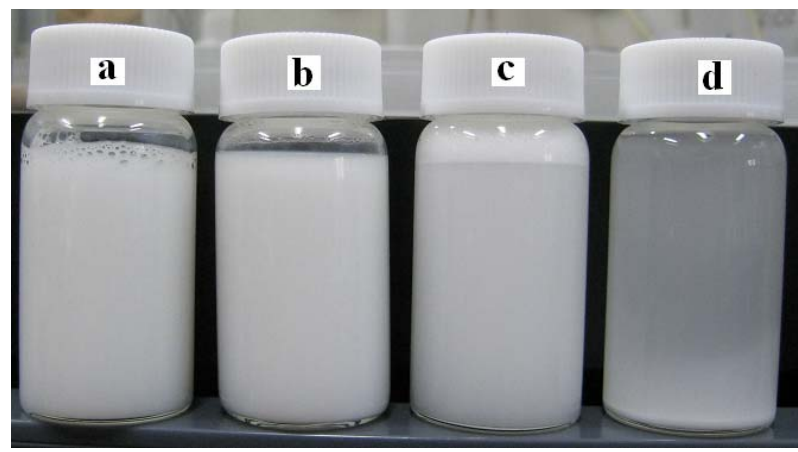

Figure 2. Milky state of the emulsion prepared with Span 20 (a), keep for 48 h (b), Tween 20 (c), and keep for 24 h (d).

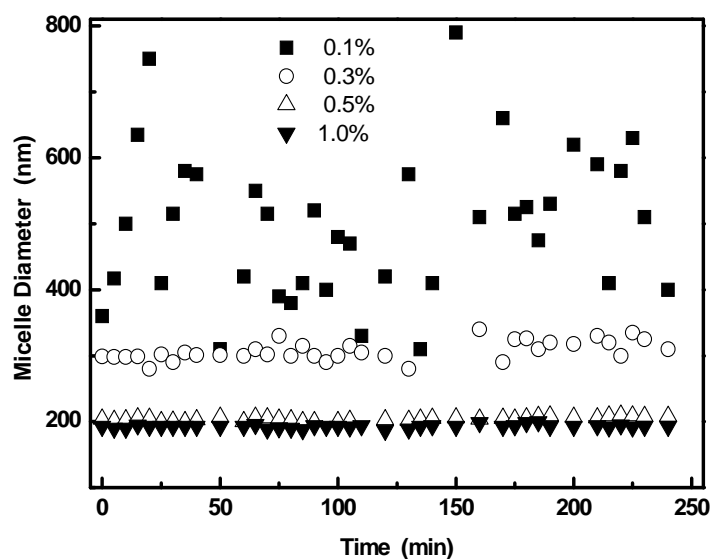

Figure 3. Micelle diameter at various concentrations of Span 20, (匹) $0.1 \%,(\circ) 0.3 \%,(\Delta) 0.5 \%$ and $(\nabla) 1.0 \%$.

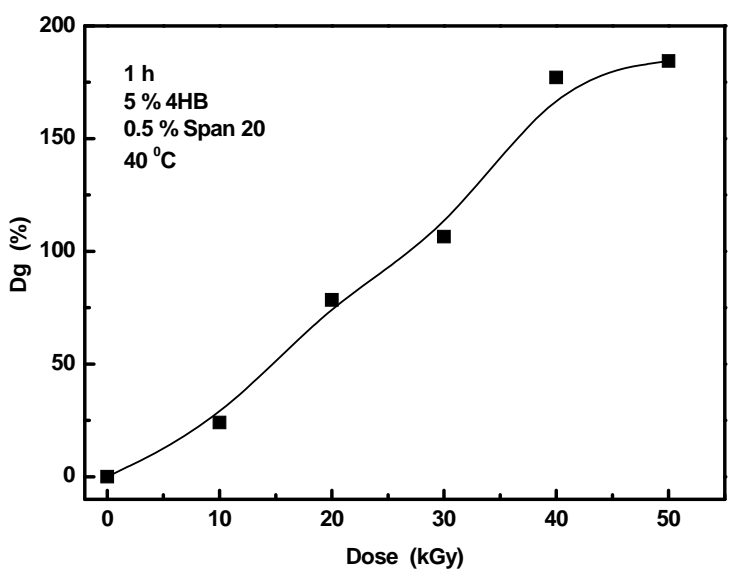

Figure 4. Effect of pre-irradiation dose on $D_{g}$, with $5 \%$ 4-HB, $0.5 \%$ Span-20 at $40^{\circ} \mathrm{C}$ after $1 \mathrm{~h}$ grafting.

$50 \mathrm{kGy}$. It is well known that pre-irradiation induced graft copolymerization relies heavily on the amount of trapped radicals generated in the trunk polymer. The linearly increased $D_{g}$ is due to the amount of efficient trapped radicals with the dose increment, which is accompanied by an increment in the initiation, followed by predominance in propagation and suppression in termination [38]. However, as already reported in literature, once the rate of graft polymerization is too high to exceed the diffusion rate of monomer into the fabric, the simultaneous cross-linking in the fabric suppresses the diffusion of 4-HB into polyethylene [39]. Hence, preirradiation dose below $50 \mathrm{kGy}$ is considered to be favorable for 4-HB graft polymerization onto PE/PP NF.

Figure 5 shows the effect of 4-HB concentration on $\mathrm{D}_{\mathrm{g}}$ in the case of $50 \mathrm{kGy}$ pre-irradiation at $40^{\circ} \mathrm{C}$ after fixed time interval of $0.5,1,2,3$ and $4 \mathrm{~h}$. Set grafting time of $1 \mathrm{~h}$ for example, a concentration of $2.5 \%$ 4-HB yielded a $\mathrm{D}_{\mathrm{g}}$ of $60 \%$. At the concentration of $5 \%$ the $\mathrm{D}_{\mathrm{g}}$ reached $175 \%$ which is enough for precursor for application to metal ion adsorbent [39]. Then the increase of concentration led a slower increment and gave a platform value of $290 \%$ at the concentration of $15 \%$. The further increase of 4-HB concentration would result in a homo-polymerization, which turned out to be uneconomical and unnecessary. Evidence from the above suggests a concentration of 5\% 4-HB would be appropriate for this graft polymerization.

Figure 6 shows the time conversion of $\mathrm{D}_{\mathrm{g}}$ at $40^{\circ} \mathrm{C}$ in the aqueous emulsion of $5 \% 4-\mathrm{HB}$ at pre-irradiation dose of 30 and $50 \mathrm{kGy}$, respectively. At pre-irradiation dose of $50 \mathrm{kGy}, \mathrm{D}_{\mathrm{g}}$ increased drastically with grafting time and reached $130 \%$ after $30 \mathrm{~min}$, and gradually leveled off after $3 \mathrm{~h}$ with a $\mathrm{D}_{\mathrm{g}}$ of $280 \%$. As the diffusion rate of the monomer to the internal radicals in the polymer substrate was impeded by graft polymerization and homo-polymerization, and eventually resulted in a certain value of $\mathrm{D}_{\mathrm{g}}$. At pre-irradiation dose of $30 \mathrm{kGy}, \mathrm{D}_{\mathrm{g}}$ increased steadily with grafting time and reached $130 \%$ after $2 \mathrm{~h}$. As a $\mathrm{D}_{\mathrm{g}}$ of $130 \%$ is enough for precursor for application to metal ion adsorbent, it is more economical and easier to control the $\mathrm{D}_{\mathrm{g}}$ at the dose of $30 \mathrm{kGy}$ rather than $50 \mathrm{kGy}$.

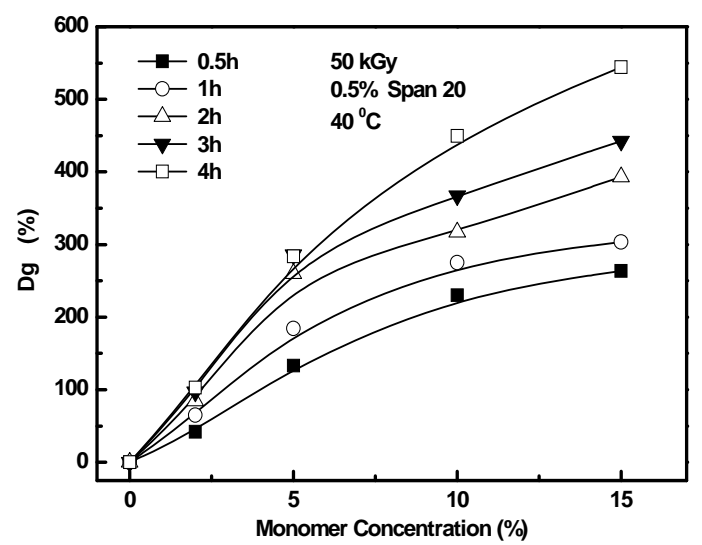

Figure 5. Effect of monomer concentration on $D_{g}$, after 50 kGy irradiation with $0.5 \%$ Span 20 at $40^{\circ} \mathrm{C}$, (ש) $0.5 \mathrm{~h}$, (०) 1 h, ( $\Delta) 2 \mathrm{~h},(\nabla) 3 \mathrm{~h}$ and ( $\square) 4 \mathrm{~h}$. 


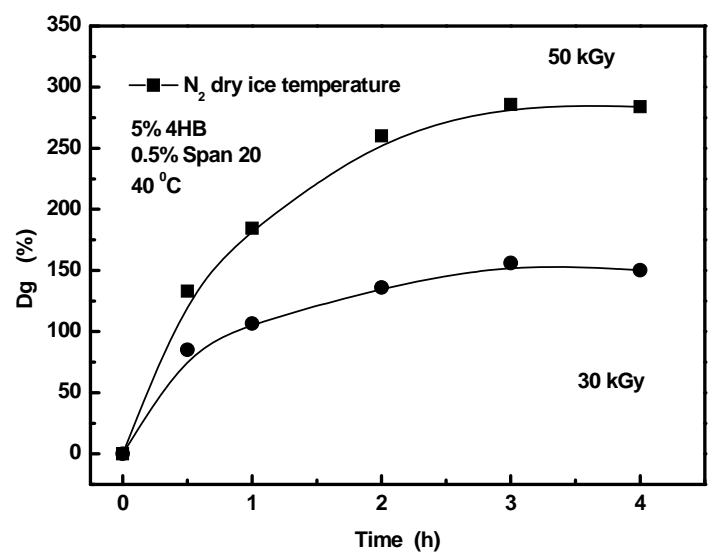

Figure 6. Time course of 4-HB grafting on NF, (a) 50 kGy and (•) $30 \mathrm{kGy}$ irradiation dose.

The graft polymerization of NF with 4-HB was demonstrated by FT-IR. An example of a spectrum is given in Figure 7 together with a spectrum of the trunk polymer. After the NF was grafted with 4-HB, the strong absorption at about $1726 \mathrm{~cm}^{-1}(\mathrm{C}=\mathrm{O}$ stretching $)$ and 1251 $\mathrm{cm}^{-1}$ (-C-O- stretching) were observed. Besides, 847 $\mathrm{cm}^{-1}$ represented the characteristic vibrations of epoxy groups. Meanwhile, the characteristic vibrations of the carbonyl group increased with the increase of $D_{g}$. These results indicate that the introduction of poly-4-HB onto $\mathrm{PE} / \mathrm{PP}$ fabric is clearly produced.

The SEM images of the surface sections of trunk NF and grafted material are shown in Figure 1. The surface section image of the fabric revealed the fiber morphology, crisscrossed by a network of fibers with $10 \mu \mathrm{m}$ in di- ameter (Figure 1(a)). After graft polymerization, the diameter of the fiber was doubled to $20 \mu \mathrm{m}$ at the $\mathrm{D}_{\mathrm{g}}$ of $130 \%$ (Figure 1(b)). In our previous study, the soft trunk NF became hard after grafted with GMA and then turned to brittle at a high $\mathrm{D}_{\mathrm{g}}$ of $100 \%$. However the 4-HB grafted-type material can keep soft even at a high $\mathrm{D}_{\mathrm{g}}$ of $280 \%$. The tensile curves are displayed in Figure 8, in which the three curves followed the similar propensity but with some discrepancy. From tensile strength and breaking elongation of single NF it is clearly that the GMA grafted NF can easily be broken under tension compared with 4-HB grafted one. When compare the molecular structure of 4-HB with GMA depicted in Figure 1 the reason can be presumed as the 4 methylene groups of 4-HB. This subtle distinction makes the molecular structure of monomer flexible, further makes the side chain of polymer longer and flexible during the process of graft polymerization. Accordingly, not only the physical properties such as topography and mechanical properties of the grafted material but also their capability were improved, which will be elaborated below.

\subsection{Modification of PE-g-P4-HB}

All above results show that the optimum conditions to prepare 4-HB-grafted NF have been achieved by using relatively low irradiation dose at $30 \mathrm{kGy}$, low monomer concentration of $5 \%$. And then amine-type adsorbents were synthesized by reaction of EDA with 4-HB grafted $\mathrm{NF}$. Figure 7c shows the infrared spectra of the grafted NF with EDA group contents. As compared to the spectrum of the unmodified copolymers (Figure $7(\mathbf{b})$ ), the

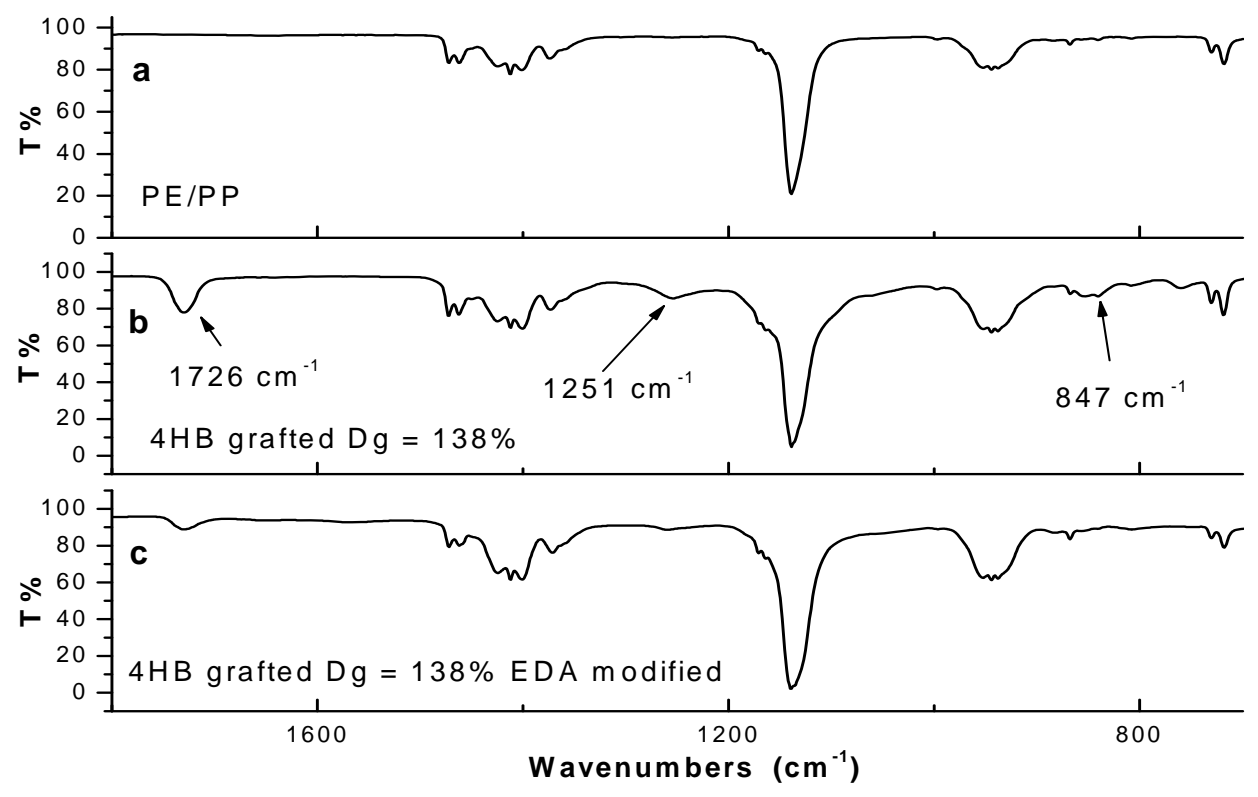

Figure 7. FT-IR spectra of NF, 4-HB-grafted NF and modified 4-HB-grafted NF with EDA. 


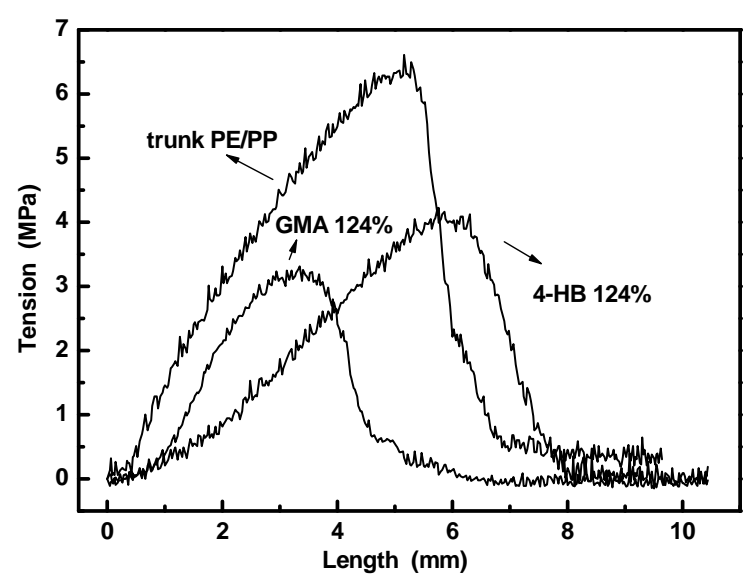

Figure 8. The typical tensile curves of NF, 4-HB-grafted NF and GMA-grafted NF.

characteristic vibrations of epoxy groups at $847 \mathrm{~cm}^{-1}$ disappeared because of the ring opening reaction. The density of amine group in EDA modified NF with different $D_{g}$ were shown in Figure 9. In the case of material with low $\mathrm{D}_{\mathrm{g}}$ the density of amine group almost linearly depended on the $\mathrm{D}_{\mathrm{g}}$, which also indicated that amine group could easily be introduced into grafted poly-4-HB. After modification, a $\mathrm{D}_{\mathrm{g}}$ of $100 \%$ 4-HB-grafted NF yielded 2.5 mmol-epoxy groups in $1 \mathrm{~g}$ grafted material. The density of amine group preserved increasing but the ratio slowed down distinctly and finally reached a plateau value of $3.0 \mathrm{mmol} / \mathrm{g}$ at the $\mathrm{D}_{\mathrm{g}}$ of $290 \%$. In the SEM image shown in Figure 1 the modified material seemed similar with the unmodified NF, which means no trail of destruction happened during the modification process.

\subsection{Absorptive Property of Modified Adsorbents}

The grafted NF with a $\mathrm{D}_{\mathrm{g}}$ of $135 \%$ was treated by EDA at the optimized condition of modification, and the density of amine group was $2.8 \mathrm{mmol} / \mathrm{g}$. Metal adsorption of the resulting adsorbent NF was performed by batch adsorption of $10 \mathrm{ppm}$ metal ions. The absorptive behavior of the material depended on the $\mathrm{pH}$ value of the solution (Figure 10). Generally, the removal ratio of the metal ions increased with the increment of $\mathrm{pH}$ value and reached a platform of $95 \%$ for $\mathrm{Cu}^{2+}, 82 \%$ for $\mathrm{Pb}^{2+}$ and $73 \%$ for $\mathrm{Zn}^{2+}$ respectively at $\mathrm{pH} 5$ after $5 \mathrm{~h}$ adsorption. The capability of this EDA modified NF was also studied in $\mathrm{Ni}^{2+}$ and $\mathrm{Li}^{+}$solutions. However, the removal ratio was very low. After $24 \mathrm{~h}$, removal ratio of $\mathrm{Ni}^{2+}$ at $\mathrm{pH} 5$ was only $23 \%$ (Figure 11). In the case of $\mathrm{Li}^{+}$, EDA modified NF was almost impotent (Figures 10, 11). Hence, the removal ratio of the EDA modified adsorbent is in the order of $\mathrm{Cu}^{2+}>\mathrm{Pb}^{2+}>\mathrm{Zn}^{2+}>\mathrm{Ni}^{2+}>\mathrm{Li}^{+}$.

When compare the capability of 4-HB-grafted material with GMA-grafted one, certain $\mathrm{D}_{\mathrm{g}}$ was designed before

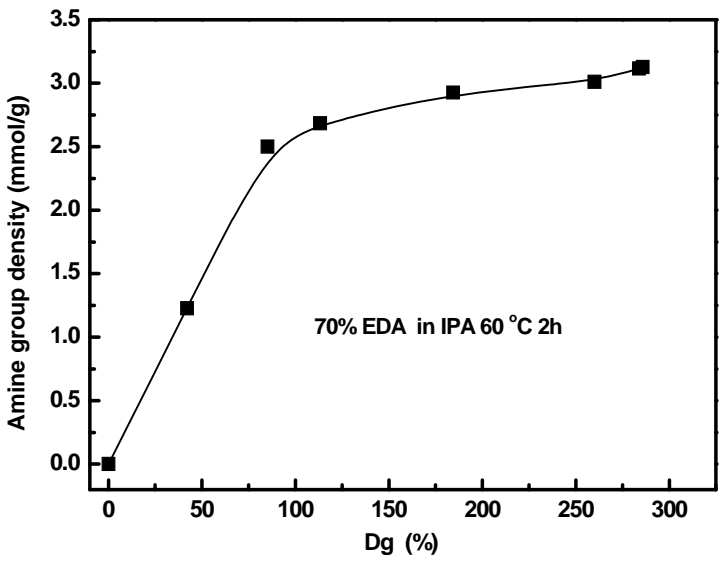

Figure 9. The density of amine groups in EDA-type adsorbents after $2 \mathrm{~h}$ modification at $60^{\circ} \mathrm{C}$.

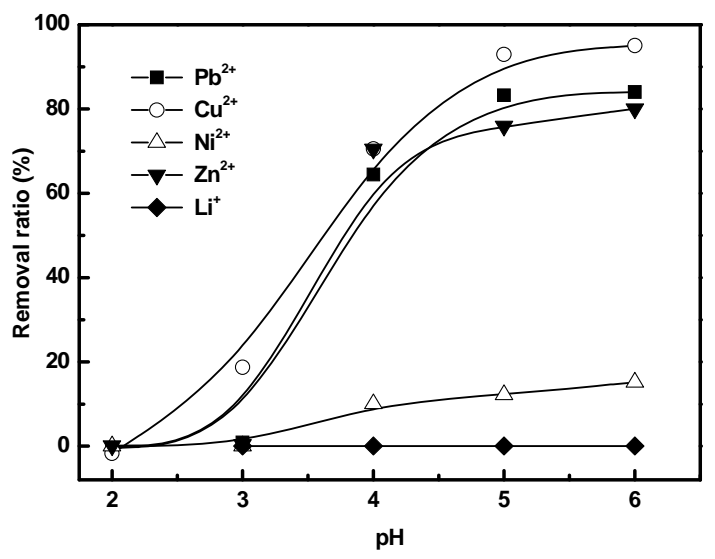

Figure 10. Removal ratio of metal ions at different $\mathrm{pH}$ values, (a) $\mathrm{Pb}^{2+},(\circ) \mathrm{Cu}^{2+},(\Delta) \mathrm{Ni}^{2+},(\nabla) \mathrm{Zn}^{2+}$ and (४) $\mathrm{Li}^{+}$.

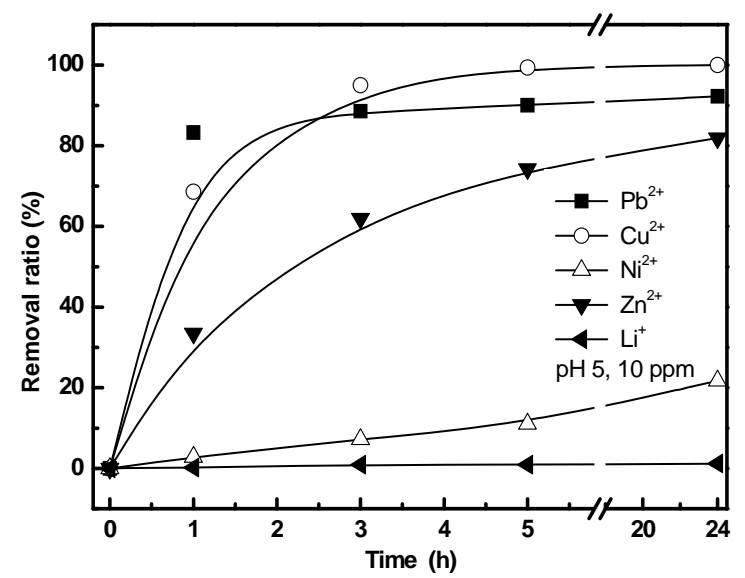

Figure 11. Removal ratio of metal ions with initial concentration of $10 \mathrm{ppm}$ at $\mathrm{pH} 5,(\mathrm{a}) \mathrm{Pb}^{2+},(\circ) \mathrm{Cu}^{2+},(\Delta) \mathrm{Ni}^{2+},(\boldsymbol{\nabla})$ $\mathrm{Zn}^{2+}$ and (४) $\mathrm{Li}^{+}$.

hand in order to control the density of amine groups. After treated by EDA the 4-HB-grafted NF with a $\mathrm{D}_{\mathrm{g}}$ of 
$135 \%$ had an EDA density of $2.8 \mathrm{mmol} / \mathrm{g}$. The conversion of epoxy group was more than $95 \%$. In the case of GMA, a $\mathrm{D}_{\mathrm{g}}$ of $100 \%$ gave an EDA density of $3.0 \mathrm{mmol} / \mathrm{g}$. As displayed in Figure 12, the different molecular structure of 4-HB and GMA led different side chain of the polymer and eventually resulted in different absorptive capability of metal ions. After 3 days' adsorption, the removal ratio of $\mathrm{Cu}^{2+}$ and $\mathrm{Pb}^{2+}$ from both 4-HB and GMA grafted material could reach more than $95 \%$. However, for both $\mathrm{Cu}^{2+}$ and $\mathrm{Pb}^{2+}$ the removal ratio from the 4-HB-grafted material increased more rapidly than the GMA-grafted as time went on (Figure 12). Especially for $\mathrm{Cu}^{2+}$, after $5 \mathrm{~h}$ adsorption 4-HB-grafted material showed a removal ration of about $90 \%$, while the GMA-grafted one only $60 \%$. As mentioned above, the 4 methylene groups of 4-HB make the side chain longer and flexible. Hook shaped functional groups on the side chain stands for the chelation of metal ions. With the long and flexible side chain, the mobility of the amine functional groups is enhanced and it is easier to catch the target ion. For the radius of a single ion, $\mathrm{Pb}^{2+}$ is much larger $(0.120 \mathrm{~nm})$ than $\mathrm{Cu}^{2+}(0.072 \mathrm{~nm})$. Hence, the adsorption rate of the 4-HB-grafted is higher than that of the GMA-grafted, especially for the smaller ions of $\mathrm{Cu}^{2+}$. After soaking in the $10 \mathrm{ppm}$ solution for $5 \mathrm{~h}$, the 4-HB-grafted adsorbent presented a removal ratio of $96 \%$ for $\mathrm{Cu}^{2+}$ and $93 \%$ for $\mathrm{Pb}^{2+}$, respectively. That means the selectivity of $\mathrm{Cu}^{2+}$ is slightly higher than that of $\mathrm{Pb}^{2+}$. However, in the case of GMA-grafted, after $5 \mathrm{~h}$ adsorption the removal ratio for $\mathrm{Cu}^{2+}$ is only $60 \%$ and for $\mathrm{Pb}^{2+}$ is $93 \%$. That means the selectivity of $\mathrm{Pb}^{2+}$ is much higher than that of $\mathrm{Cu}^{2+}$. As a consequence, the less soft GMAtype material can catch the bigger $\mathrm{Pb}^{2+}$ ion efficiently. Subtle distinction of 4 methylene groups of 4-HB gave birth to a remarkable progress of not only mechanical

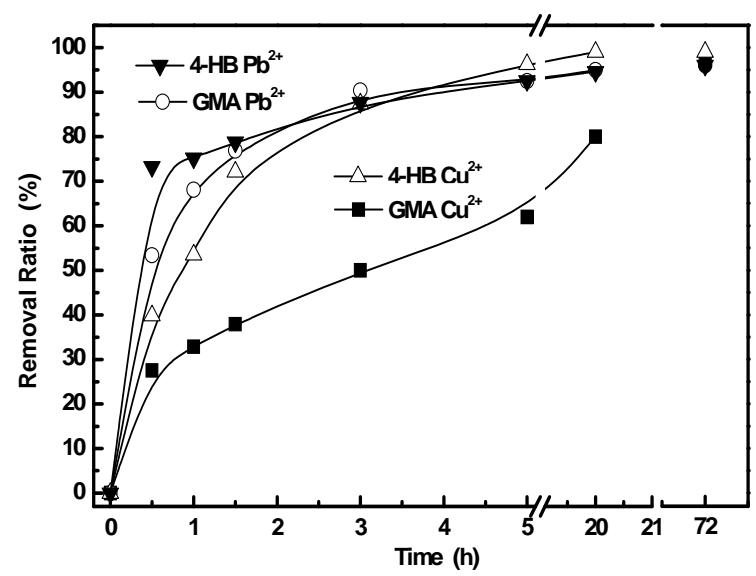

Figure 12. Removal ratio of metal ions from (a) GMAgrafted $\mathrm{NF}$ for $\mathrm{Cu}^{2+},(\circ)$ GMA-grafted $\mathrm{NF}$ for $\mathrm{Pb}^{2+},(\Delta)$ 4-HB-grafted $\mathrm{NF}$ for $\mathrm{Cu}^{2+}$ and $(\nabla)$ 4-HB-grafted $\mathrm{NF}$ for $\mathrm{Pb}^{2+}$. property but also higher adsorption capacity. Relevant theoretical research is now continuing and the detail of the mechanism is expected in the next paper.

\section{Conclusions}

4-HB can be grafted onto NF with a pre-irradiation method. Stable emulsion of 4-HB was prepared with 0.5 $w t \%$ Span 20 in water. The optimum conditions to prepare 4-HB-grafted NF have been achieved by using relatively low irradiation dose at $30 \mathrm{kGy}$, low monomer concentration of $5 \%$ with the surfactant of $0.5 \%$ Span 20 at $40^{\circ} \mathrm{C}$. After $2 \mathrm{~h}$, the trunk polymer is made grafted at a $\mathrm{D}_{\mathrm{g}}$ of $135 \%$. 4-HB-grafted NF was modified by EDA in IPA as a solvent at $60^{\circ} \mathrm{C}$. With a $\mathrm{D}_{\mathrm{g}}$ of $135 \%$, the adsorbent shows an amine group density of $2.8 \mathrm{mmol} / \mathrm{g}$. The adsorption test was carried out by batch experiment in several metal ion solutions, and the removal ratio from the EDA modified adsorbent of the metal ions is in the order of $\mathrm{Cu}^{2+}>\mathrm{Pb}^{2+}>\mathrm{Zn}^{2+}>\mathrm{Ni}^{2+}>\mathrm{Li}^{+}$. The removal ratio of the metal ions increased with the increment of $\mathrm{pH}$ value and reached a platform of $95 \%$ for $\mathrm{Cu}^{2+}, 82 \%$ for $\mathrm{Pb}^{2+}$ and $73 \%$ for $\mathrm{Zn}^{2+}$ at $\mathrm{pH} 5$ after $5 \mathrm{~h}$ adsorption in $10 \mathrm{ppm}$ metal ion solutions. After $24 \mathrm{~h}$, the removal ratio of $\mathrm{Ni}^{2+}$ at $\mathrm{pH} 5$ was only $23 \%$, and $\mathrm{Li}^{+}$cannot be removed from the solution. Compared with GMA, subtle distinction of 4 methylene groups of 4-HB gave birth to a remarkable progress of the material. The longer side chain makes the material more flexible. Hence, 4-HB-grafted adsorbent exhibited not only better mechanical property but also higher adsorption capacity when it is used to remove $\mathrm{Cu}^{2+}$ and $\mathrm{Pb}^{2+}$ from solution. The long methylene unit would be a promising improvement of the adsorbents.

\section{REFERENCES}

[1] R. Molinari, T. Poerio, R. Cassano, N. Picci and P. Argurio, "Copper(II) Removal from Wastewaters by a New Synthesized Selective Extractant and SLM viability," Industrial \& Engineering Chemistry Research, Vol. 43, No. 2, 2004, pp. 623-628.

[2] M. M. Beppu, E. J. Arruda, R. S. Vieira and N. N. Santos, "Adsorption of $\mathrm{Cu}(\mathrm{II})$ on Porous Chitosan Membranes Functionalized with Histidine," Journal of Membrane Science, Vol. 240 No. 1-2, 2004, pp. 227-235. doi:10.1016/j.memsci.2004.04.025

[3] I. Renberg, M. L. Brännval, R. Bindler and O. Emteryd, "Stable Lead Isotopes and Lake Sediments-A Useful Combination for the Study of Atmospheric Lead Pollution History," Science of the Total Environment, Vol. 292, No. 1-2, 2002, pp. 45-54. doi:10.1016/S0048-9697(02)00032-3

[4] O. Andersen, "Principles and Recent Developments in Chelation Treatment of Metal Intoxication," Chemical Review, Vol. 99, No. 9, 1999, pp. 2683-2710.

doi:10.1021/cr980453a 
[5] S. Manahan, "Environmental Chemistry," Brooks/Colei, California, USA, 1984.

[6] US Environmental Protection Agency (USEPA), "Guidelines for Drinking Water," March 2001.

[7] K. V. S. G. Muralikrishna, "Chemical Analysis of Water and Soil-A Laboratory Manual, Environmental Protection Society," National Institute of Ecology and Environment, Kakinada, India, 1997.

[8] IS: 10500, Drinking Water Standards, Bureau of Indian Standards (BIS), 1995.

[9] R. Gündŏgan, B. Acemiŏglu and M. H. Alma, "Copper (II) Adsorption from Aqueous Solution by Herbaceous Peat," Journal of Colloid and Interface Science, Vol. 269, No. 2, 2004, pp. 303-309. doi:10.1016/S0021-9797(03)00762-8

[10] T. A. Garcia and L. Corredor, "Biochemical Changes in the Kidneys after Perinatal Intoxication with Lead and/or Cadmium and Their Antagonistic Effects When Coadministered," Ecotoxicology Environmental Safety, Vol. 57, No. 2, 2004, pp. 184-189. doi:10.1016/S0147-6513(03)00063-0

[11] J. Goel, K. Kadirvelu, C. Rajagopal, and V. K. Garg, "Removal of Lead(II) from Aqueous Solution by Adsorption on Carbon Aerogel Using a Response Surface Methodological Approach," Industrial \& Engineering Chemistry Research, Vol. 44, No. 7, 2005, pp. 1987-1994. doi:10.1021/ie0490684

[12] T. Tokimoto, N. Kawasaki, T. Nakamura, J. Akutagawa and S. Tanada, "Removal of Lead Ions in Drinking Water by Coffee Grounds as Vegetable Biomass," Journal of Colloid and Interface Science, Vol. 281, No. 1, 2005, pp. 56-61. doi:10.1016/j.jcis.2004.08.083

[13] C. Huang, Y. C. Chung and M.R. Liou, "Adsorption of $\mathrm{Cu}(\mathrm{II})$ and $\mathrm{Ni}(\mathrm{II})$ by Pelletized Biopolymer," Journal of Hazardous Materials, Vol. 45, No. 2-3, 1996, pp. 265277. doi:10.1016/0304-3894(95)00096-8

[14] G. Issabayeva, M. K. Aroua and N. M. Nik Sulaiman, "Removal of Lead from Aqueous Solutions on Palm Shell Activated Carbon," Bioresource Technology, Vol. 97, No. 18, 2006, pp. 2350-2355. doi:10.1016/j.biortech.2005.10.023

[15] K. Chandra Sekhar, C. T. Kamala, N.S. Chary, A. R. K. Sastry, T. Nageswara Rao and M. Vairamani, "Removal of Lead from Aqueous Solutions Using an Immobilized Biomaterial Derived from a Plant Biomass," Journal of Hazardous Materials, Vol. 108, No. 1-2, 2004, pp. 111117. doi:10.1016/i.jhazmat.2004.01.013

[16] A. Janin, J. F. Blais, G. Mercier and P. Drogui, "Selective Recovery of $\mathrm{Cr}$ and $\mathrm{Cu}$ in Leachate from Chromated Copper Arsenate Treated Wood Using Chelating and Acidic Ion Exchange Resins," Journal of Hazardous Materials, Vol. 169, No. 1-3, 2009, pp. 1099-1105. doi:10.1016/j.jhazmat.2009.04.066

[17] M. M. Beppu, E. J. Arruda, R. S. Vieira and N. N. Santos, "Adsorption of $\mathrm{Cu}(\mathrm{II})$ on Porous Chitosan Membranes Functionalized with Histidine," Journal of Membrane Science, Vol. 240, No. 1-2, 2004, pp. 227-235.
[18] A. Saeed, M. Iqbal and M. W. Akhtar, "Removal and Recovery of Lead(II) from Single and Multimetal $(\mathrm{Cd}, \mathrm{Cu}$, $\mathrm{Ni}, \mathrm{Zn}$ ) Solutions by Crop Milling Waste (Black Gram Husk)," Journal of Hazardous Materials, Vol. 117, No. 1, 2005, pp. 65-73. doi:10.1016/j.jhazmat.2004.09.008

[19] R. S. Yeh, Y. Y. Wang and C. C. Wan, "Removal of $\mathrm{Cu}$-EDTA Compounds Via Electrochemical Process With Coagulation," Water Research, Vol. 29, No. 2, 1995, pp. 597-599. doi:10.1016/0043-1354(94)00169-8

[20] H. Cheng, "Cu(II) Removal from Lithium Bromide Refrigerant by Chemical Precipitation and Electrocoagulation," Separation and Purification Technology, Vol. 52, No. 1, 2006, pp. 191-195. doi:10.1016/j.seppur.2006.03.021

[21] M. Q. Jiang, X. Y. Jin, X. Q. Lu and Z. L. Chen, "Adsorption of $\mathrm{Pb}(\mathrm{II}), \mathrm{Cd}(\mathrm{II}), \mathrm{Ni}(\mathrm{II})$ and $\mathrm{Cu}(\mathrm{II})$ onto Natural Kaolinite Clay," Desalination, Vol. 252, No. 1-3, 2010, pp. 33-39. doi:10.1016/j.desal.2009.11.005

[22] J. Oliva, J. De Pablo, J. L. Cortina, J. Cama and C. Ayora, "The Use of Patite II to Remove Divalent Metal Ions Zinc(II), Lead(II), Manganese(II) and Iron(II) from Water in Passive Treatment Systems: Column Experiments," Journal of Hazardous Materials, Vol. 184, No. 1-3, 2010, pp. 364-374. doi:10.1016/j.jhazmat.2010.08.045

[23] Y. Xu and D. Zhao, "Removal of Lead from Contaminated Soils Using Poly(Amidoamine) Dendrimers," Industrial \& Engineering Chemistry Research, Vol. 45 No. 5, 2006, pp. 1758-1765.

[24] H. Chen and A. Wang, "Adsorption Characteristics of $\mathrm{Cu}$ (II) from Aqueous Solution onto Poly(Acrylamide)/ Attapulgite Composite," Journal of Hazardous Materials, Vol. 165, No. 1-3, 2009, pp. 223-231. doi:10.1016/i.jhazmat.2008.09.097

[25] A. Nagendran, A. Vijayalakshmi, D. Lawrence Arockiasamy, K. H. Shobana and D. Mohan, "Toxic Metal Ion Separation by Cellulose Acetate/Sulfonated Poly(Ether Imide) Blend Membranes: Effect of Polymer Composition and Additive Original Research Article," Journal of Hazardous Materials, Vol. 155, No. 3, 2008, pp. 477-485. doi:10.1016/j.jhazmat.2007.11.088

[26] K. Saito, S. Yamada, S. Furusaki, T. Sugo and J. Okamoto, "Characteristics of Uranium Adsorption by Amidoxime Membrane Synthesized by Radiation-Induced Graft Polymerization," Journal of Membrane Science, Vol. 34, No. 1, 1987, pp. 307-315. doi:10.1016/S0376-7388(00)83171-3

[27] M. M. Nasef, H. Saidi and H. Mohd Nor, "RadiationInduced Graft Copolymerization for Preparation of Cation Exchange Membranes: A Review," Malaysia Nuclear Science Journal, Vol. 17, 1999, pp. 27-43.

[28] T. Kawai, K. Sugita, K. Saito and T. Sugo, "Extension and Shrinkage of Polymer Brush Grafted onto Porous Membrane Induced by Protein Binding," Macromolecules, Vol. 33, No. 4, 2000, 1306-1309. doi: $10.1021 / \mathrm{ma} 9819642$

[29] F. Cardona, G. A. George, D. J. T. Hill, F. Rasoul and J. Maeji, "Copolymers Obtained by the Radiation-Induced 
Grafting of Styrene onto Poly(Tetrafluoroethylene-CoPerfluoropropylvinyl Ether) Substrates. 1. Preparation and Structural Investigation," Macromolecules, Vol. 35, No. 2, 2002, pp. 355-364. doi:10.1021/ma0022295

[30] M. Tamada, N. Seko and F.Yoshii, "Application of Radiation-Graft Materials for Metal Adsorbent and Crosslinked Natural Polymer for Healthcare Products," Radiation Physics and Chemistry, Vol. 71, No. 1-2, 2004, pp. 223-227. doi:10.1016/j.radphyschem.2004.03.044

[31] N. Seko, A. Katakai, S. Hasegawa, M. Tamada, N. Kasai, H. Takeda, T. Sugo and K. Saito, "Aquaculture of Uranium in Seawater by a Fabric-Adsorbent Submerged System," Nuclear Technology, Vol. 144, No. 2, 2003, pp. 274-278.

[32] N. Seko, M. Tamada and F. Yoshii, "Current Status of Adsorbents for Metal Ions with Radiation Grafting and Crosslinking Technique," Nuclear Instrument and Methods in Physics Research Section B: Beam Interactions with Materials and Atoms, Vol. 236, No. 1, 2005, pp. 21-29. doi:10.1016/j.nimb.2005.03.244

[33] H. Kawakita, K. Uezu, S. Tsuneda, K. Saito, M. Tamada and T. Sugo, "Recovery of $\mathrm{Sb}(\mathrm{V})$ Using a FunctionalLigand-Containing Porous Hollow-Fiber Membrane Prepared by Radiation-Induced Graft Polymerization," $\mathrm{Hy}$ drometallurgy, Vol. 81, No. 3-4, 2006, pp. 190-196. doi:10.1016/j.hydromet.2005.12.010

[34] A. W. Eckert, D. Grobe and U. Rothe, "Surface-Modification of Polystylene-Microtitre Plates via Grafting of
Glycidylmethacrylate and Coating of Poly-Glycidylmethacrylate," Biomaterials, Vol. 21, No. 5, 2000, pp. 441-447. doi:10.1016/S0142-9612(99)00098-8

[35] H. Hoshina, N. Seko, Y. Ueki and M. Tamada, "Synthesis of Graft Adsorbent with N-methyl-D-glucamine for Boron Adsorption," Journal of Ion Exchange, Vol. 18, No. 1-2, 2007, pp. 236-239.

[36] C. A. Flemming and J. T. Trevors, "Copper Toxicity and Chemistry in the Environment: A Review," Water Air Soil Pollution, Vol. 44, No. 1-2, 1989, pp. 143-158. doi:10.1007/BF00228784

[37] A. Sekine, N. Seko, M. Tamada and Y. Suzuki, "Biodegradable Metal Adsorbent Synthesized by Graft Polymerization onto Nonwoven Cotton Fabric," Radiation Physics and Chemistry, Vol. 79, No. 1, 2010, pp. 16-21. doi:10.1016/j.radphyschem.2009.08.007

[38] M. M. Nasef, H. Saidi and K. Z. M. Dahlan, "Kinetic Investigations of Graft Copolymerization of Sodium Styrene Sulfonate onto Electron Beam Irradiated Poly(Vinylidene Fluoride) Films," Radiation Physics and Chemistry, Vol. 80, No. 1, 2011, pp. 66-75. doi:10.1016/i.radphyschem.2010.08.010

[39] N. Seko, L. T. Bang and M. Tamada, "Synthesis of Amine-Type Adsorbents with Emulsion Graft Polymerization of Glycidyl Methacrylate," Nuclear Instrument and Methods in Physics Research Section B: Beam Interactions with Materials and Atoms, Vol. 265, No. 1, 2007, pp. 146-149. doi:10.1016/j.nimb.2007.08.041 